\title{
College Students' Knowledge and Perspective Towards Biodiversity and its Conservation and Protection
}

\author{
Ericson Esquibel Coracero ${ }^{1,3^{*}}$, Mark Christian Facun ${ }^{1}$, Marlon Lingon', Kristina Lolong2, Michelle Lugayan ${ }^{2}, K^{1}$ arl \\ Benz Montesines ${ }^{1}$, Lesel Sangalang ${ }^{2}$, Mark John Suniega ${ }^{1}$ \\ 1 Department of Forestry and Environmental Sciences, Aurora State College of Technology, Baler, Aurora, \\ Philippines 3200 \\ 2 Department of Arts and Sciencesx, Aurora State College of Technology, Baler, Aurora, Philippines 3200 \\ 3 Department of Graduate Studies, Aurora State College of Technology, Baler, Aurora, Philippines 3200 \\ * Correspondence: ericsoncoracero@ascot.edu.ph; Tel.: +639634900319
}

\begin{abstract}
Rich biodiversity is one of the Philippines' greatest assets. Unfortunately, there is a continuous decline in the diversity of flora and fauna across the world. This calls for the need to educate people, especially younger generations, to value and protect biodiversity and natural resources. The study aimed to assess the students' extent of knowledge and identify their perspectives towards biodiversity and its protection and conservation. A total of 268 randomly selected students at Aurora State College of Technology Zabali Campus were involved in the study. Survey questionnaires were used to obtain data and information which were subjected to statistical tests. The students had a moderate knowledge level on biodiversity with a mean score of 6.65 out of 10 items $(\mathrm{SD}=1.50)$. Their perspective on biodiversity was leaning toward its protection and conservation, with a mean score of 7.2 out of 10 items $(S D=1.29)$. Factors affecting the students' knowledge were gender $(p=.003)$ and academic department $(p=0.003)$. Females and those associated with the Department of Forestry and Environmental Sciences and Department of Industrial technology were found to have more knowledge than the others. Males, on the other hand, were found to have a more positive perspective towards biodiversity. Knowledge and perspective had a weak correlation with $r=0.39$. Students were not well-aware, but were in support of the Philippines' biodiversity-related laws, which could help shape their mindset and actions towards biodiversity conservation and protection. As an implication, the college administration must revisit the curricula of all degree programs and ensure that students from each degree program are environmentally educated, emphasizing biodiversity conservation.
\end{abstract}

Keywords: biodiversity education, knowledge, perspective, biodiversity conservation, biodiversity protection

\section{Introduction}

The environment and natural resources, including forests, are the primary sources of life for most of the world's population. The International Fund for Agricultural Development (IFAD) in 2012 highlighted the importance of healthy forests and a high level of biodiversity in maintaining the world's ecosystems that support the lives of billions of people [1]. By definition, a forest is a "land spanning more than 0.5 hectares with trees higher than 5 meters and a canopy cover of more than 10 percent, or trees able to reach these thresholds in situ which does not include land that is predominantly under agricultural or urban land use" [2]. Biodiversity is defined by studies and organizations as the variability among life forms on Earth (plants, animals, bacteria, and such) [3,4]. Another definition of biodiversity is provided in the study of van Weelie and Boersma (2018) considering biodiversity as a natural resource, as nature or environment, and as index of measurement summarizing it as variability in biological objects in space and time [5]. It has three levels or components - ecosystem, species, and genetic diversity [6]. 
Unfortunately, both of the world's forests and biodiversity are generally decreasing at an unpleasant rate that dictates the call for immediate conservation and protection of these resources [7].

Human activities are one of the most influential factors in bringing changes to the environment. These changes could be positive if actions are pro-environment such as reforestation and other cleaning and greening activities. On the other hand, effects could be abominable if the activities (forest degradation, deforestation, and other destructive actions) conducted can inflict harm to the environment [8]. Each country should involve its people in protecting the environment and natural resources [9]. Government and nongovernment efforts are encouraged to sustain and save the environment preventing drastic and worse resource deterioration [10].

However, there are prerequisites in effectively devising and executing management measures for conservation and protection of the natural resources - knowledge [11] and perspective [12]. Knowledge can be obtained through education [13]. It is impossible for a smooth flow of conservation and management projects without education, information, and awareness regarding the matter [14]. In essence, these bodies of knowledge from education are important tools in achieving conservation and management successes [15]. Meanwhile, perspective deals with the interpretation or point of view of a person. It can be a predictive tool of his behavior or action towards something [16]. Thus, understanding one's perspective can help determine his or her attitude towards the conservation and management activities being or will be employed.

The present generation, especially the children and youth are the two most significant actors that can prevent the total loss of biodiversity and natural resources [14]. Educating them at an early age can help improve their perspective and be fighters for biodiversity through active involvement in conservation and protection of natural resources [17]. In the Philippines, environmental education was legalized into Republic Act No. 9512 in 2008 which was known as the "National Environmental Awareness and Education Act of 2008." This law aims to integrate environmental education at all private and public-school levels including day care centers, elementary, high schools, tertiary (technical vocational and professional), and indigenous and out of school learning systems [18]. In fact, environmental education was found by a study in Bukidnon in the Philippines to be an enhancing factor on student's knowledge and concern towards the environment which made them apply it through practice and attitude at school, home, and in the community [19].

Globally, the potential of biodiversity education in addressing biodiversity-related issues is highly appreciated. As reviewed, biodiversity education was only included or addressed in Environmental Education (EE) or Education for Sustainable Development (ESD) [20]. There was really no lone biodiversity education subject to put large emphasis on the importance of biodiversity and its management. Their review also mentioned that biodiversity education began to be on the light when the Convention of Biological Diversity (CBD) released an article indicating its acknowledgement in "developing education and awareness programs to support the goal of conserving and using biodiversity in a sustainable manner." Up to now biodiversity education continues to proliferate either as EE, ESD, or biodiversity education in different levels (elementary, high school, college, etc.) which addresses biodiversity by focusing on potential linkage of biodiversity and livelihoods, agriculture, livestock, forestry, fisheries, and more [21-24].

This research was conducted in Aurora State College of Technology (Zabali Campus) to determine the extent of the students' knowledge on biodiversity and understand their perspective on biodiversity conservation and protection. Specifically, the study aims to a) 
measure the students' level of knowledge on biodiversity, b) identify the perspective of students towards biodiversity, c) recognize probable relationship between student' profile and their knowledge and perspective on biodiversity, d) know the correlation between students' knowledge on biodiversity and their perspective towards its conservation and protection, and e) assess their knowledge and perspective on Philippine biodiversity laws and policies.

\section{Materials and Methods}

The main purpose of the study is to reveal the knowledge and perspective of students towards biodiversity and its conservation and protection. The mixed-method research design was used to analyze the students' responses. This design is efficient in using both qualitative and quantitative methods to assert meanings by using words and numbers [25]. Students' responses were gathered through the survey/questionnaire method. This survey method is versatile, generalizable, and efficient [26].

\subsection{Study Group}

A total of 286 randomly selected college students at Aurora State College of Technology (ASCOT) Zabali Campus, Baler, Aurora in the Philippines was included in the conduct of the study. Among the students, 122 (42.7\%) were females and 164 (57.3\%) were males. The mean age of the participants was 20.32 or 20 years old $(S D=2.09)$ ranging from 18 to 29 years old. Students were from three academic departments of ASCOT namely, Department of Forestry and Environmental Sciences (DFES), Department of Industrial Technology (D. Ind. Tech.), Department of Information Technology (DIT), and Engineering Department (DE). Seventy-five students (26.2\%) were from DFES, 107 (37.4\%) from D. Ind. Tech., 102 (35.7\%) from DIT, and 2 (0.70\%) from DE. Moreover, 197 (68.9\%) students responded that they have already taken environmental-related courses, while the remaining $89(31.1 \%)$ said that they have not taken any environmental-related courses in the college.

\subsection{Data Collection and Analysis}

A survey questionnaire was used to obtain information from the students. Accomplished survey forms were encoded in Microsoft Excel software. The following statistical tests and analyses were computed: descriptive statistics, chi-square, and correlation.

Descriptive statistics were used to describe the knowledge and perspective levels of students. Descriptive statistics simply summarize and describe the data for a better understanding of the readers through mean, median, mode, and standard deviation [27]. Knowledge and perspective assessment scores of students were used. For the knowledge level, their correct answers corresponded to 1 point, while wrong answers were marked as 0 . For perspective evaluation, 1 point was given to their answers that lean to the improvement or welfare of biodiversity (positive perspective towards biodiversity), while answers that can harm biodiversity were marked 0 (negative perspective towards biodiversity).

Chi-square independence test was used to evaluate if students' profile has a significant relationship with their knowledge and perspective on biodiversity. Chi-square is a statistical test that is used to measure the association between two categorical variables [28]. The students' profile, a categorical variable, tested were age, gender, department, and their environmental-related subject (whether or not they have taken it). Students' scores on the assessment of their knowledge and perspective were considered as the other 
categorical variable. Age and scores were ranged/bracketed for the statistical computation (Table 1).

Table 1. Range values for age and scores on knowledge and perspective assessments

\begin{tabular}{cc}
\hline Categorical Variables & Ranged Values \\
\hline Age & 18 to 20 \\
& 21 to 24 \\
& 25 and above \\
\hline Knowledge Assessment & 0 to 4 (Low) \\
Scores & 5 to 7 (Moderate) \\
& 8 to 10 (High) \\
\hline Perspective Assessment & 0 to 4 (Negative) \\
Scores & 5 to 7 (Moderately Positive) \\
& 8 to 10 (Positive) \\
\hline
\end{tabular}

For the relationship between knowledge and perspective of students on biodiversity, correlation analysis was employed. Correlation analysis is a statistical test used to measure the monotonic association between two variables yielding correlation values ranging from +1 to -1 [29] The monotonic association of two variables can be direct and inverse. There is a direct association if as the value of one variable increases, the value of the other variable also increases. Meanwhile, the inverse association is observed when the value of the variable increases, the value of the other variable decreases. The Study of Schober et al. in 2018 also presented a conventional table to interpret the association through computed correlation coefficient (Table 2).

Table 2. The conventional approach in interpreting correlation coefficient values

\begin{tabular}{cc}
\hline Categorical Variables & Ranged Values \\
\hline $0.00-0.10$ & Negligible correlation \\
$0.10-0.39$ & Weak Correlation \\
$0.40-0.69$ & Moderate correlation \\
$0.70-0.89$ & Strong correlation \\
$0.90-1.0$ & Very strong correlation \\
\hline
\end{tabular}

\section{Results}

\subsection{Students' Knowledge on Biodiversity}

Students' responses obtained from the knowledge assessment test revealed scores ranging from 2 to 10 out of 10 items. Descriptive statistics showed that the mean, median, and mode of all the scores in the knowledge test were $6.65,7$, and 7 , respectively with a standard deviation (SD) of 1.50. The assessment also disclosed that students were most knowledgeable in statement number 6 that "Biodiversity is everywhere." The mean score for this question was 0.95 which means that $95 \%$ (272) of all students was well-aware that biodiversity can be found everywhere (Table 3 ). On the other hand, statement number 1 had the lowest mean score of 0.20 . Therefore, 57 students $(20 \%)$ answered the question correctly. Statement 1 stated that "Biodiversity only covers the variability among living organisms found in terrestrial habitats."

Table 3. Data on the students' level of knowledge on biodiversity

No.


1 Biodiversity only covers the variability among living organisms found in terrestrial habitats. (False)

2 Invasive species negatively affect the diversity of an ecosystem. (True)

3 Evolution can replace the missing or extinct species. (False)

4 Reforestation activities can help maintain biodiversity. (True)

5 Losing a species cannot affect humans. (False)

6 Biodiversity is everywhere. (True)

$0.20 \quad 0.40 \quad 10^{\text {th }}$

$0.70 \quad 0.46 \quad 6^{\text {th }}$

$0.27 \quad 0.45 \quad 9^{\text {th }}$

$0.91 \quad 0.29 \quad 3^{\text {rd }}$

$\begin{array}{lll}0.82 & 0.38 \quad 5^{\text {th }}\end{array}$

$0.97 \quad 0.17 \quad 1^{\text {st }}$

7

Biodiversity can only be measured through the species composition, specifically in the number of species and individuals. (False)

Biodiversity plays important role in maintaining ecosystem functions (e.g., supporting, provisioning, regulating). (True)

9 All species present in the world have been discovered already. (False)

10

Changes in biological interaction like predation and parasitism can affect biodiversity. (True)
$0.65 \quad 0.48 \quad 7^{\text {th }}$

$0.29 \quad 0.46 \quad 8^{\text {th }}$

$0.95 \quad 0.21 \quad 2^{\text {nd }}$

$0.89 \quad 0.31 \quad 4^{\text {th }}$

\subsection{Students' Perspective Towards Biodiversity}

For the perspective assessment test, students' scores ranged from 3 to 10 out of 10 items. The mean, median, and mode were 7.2, 7, and 6, respectively with an SD of 1.29. It was found that students' perspectives based on statements 1 and 3 were leaning toward the welfare of the environment, particularly of biodiversity. Statement 1 said that "I believe I can do something to protect the world's biodiversity" with a mean of 0.98 (Table 4). Thus, 98\% (280) of the students believed that their actions can help protect biodiversity. Also, 99.8\% (285) of the students agreed to statement 3 - "I acknowledge the importance of 3Rs (reuse, reduce, and recycle) in conserving biodiversity." On the other hand, students were least knowledgeable on the effects of invasive species on the environment as per their response to statement 2 - "I prefer to plant invasive species like Mahogany (Swietenia macrophylla) and Ipil-ipil (Leucaena luecocephala) in an ecosystem." Only $10 \%$ (29) of the students responded that they are not in support of the idea of planting invasive species.

Table 4. Data on the students' perspective on biodiversity

\begin{tabular}{|c|c|c|c|c|}
\hline No. & Perspective & Mean & SD & Rank \\
\hline 1 & I believe I can do something to protect the world's biodiversity. & 0.98 & 0.15 & $2^{\text {nd }}$ \\
\hline 2 & $\begin{array}{l}\text { I think it is best to plant invasive species like Mahogany (Swietenia macrophylla) and } \\
\text { Ipil-ipil (Leucaena luecocephala) in an ecosystem. }\end{array}$ & 0.10 & 0.31 & $9^{\text {th }}$ \\
\hline 3 & $\begin{array}{l}\text { I acknowledge the importance of } 3 R \text { s (reuse, reduce, and recycle) in conserving } \\
\text { biodiversity. }\end{array}$ & $\begin{array}{c}1.00 \\
(0.998)\end{array}$ & 0.06 & $1^{\text {st }}$ \\
\hline 4 & $\begin{array}{l}\text { It is acceptable to utilize abundant plant species without replacing them because } \\
\text { they are still numerous in count }\end{array}$ & 0.31 & 0.46 & $8^{\text {th }}$ \\
\hline 5 & I know that shortening my shower time can conserve water. & 0.78 & 0.41 & $5^{\text {th }}$ \\
\hline 6 & $\begin{array}{l}\text { I would not mind throwing plastics in the bodies of water. It will not decrease } \\
\text { biodiversity. }\end{array}$ & 0.55 & 0.50 & $7^{\text {th }}$ \\
\hline 7 & $\begin{array}{l}\text { I know that avoidance of stepping on flowers and crops can maintain high } \\
\text { biodiversity. }\end{array}$ & 0.88 & 0.32 & $4^{\text {th }}$ \\
\hline 8 & It is okay for me to convert forestland to have malls and other establishments. & 0.69 & 0.47 & $6^{\text {th }}$ \\
\hline
\end{tabular}


9

I would like to plant at least one appropriate tree species every year to maintain biodiversity.

10

I condemn eating critically important animal species like turtles and Musang/Civet Cat (Paradoxurus hermaphroditus).

\subsection{Relationship among Students' Profile, Knowledge, and Perspective on Biodiversity}

The chi-square independence test results showed the relationship between respondents' profile and knowledge level, as well as respondents' profile and perspective of students towards biodiversity. It was found that gender and the academic department had a significant relationship with the knowledge level of students on biodiversity at $0=$ 0.05 (Table 5). Gender and knowledge level had significant relationship, $X 2(2, N=286)=$ $11.79, \mathrm{p}=.003$. Females had a higher knowledge level on biodiversity as compared with males as shown in the observed and expected values (Table 6). Association to certain academic department and knowledge level also had significant relationship, X2(6, N = $286)=19.96, p=.003$. The number of students enrolled in DFES and DIT has exceeded the expected values for having a high knowledge level on biodiversity (Table 7). On the other hand, students' gender and positive perspective towards biodiversity were found to have a significant relationship, $\mathrm{X} 2(2, \mathrm{~N}=286)=7.77, \mathrm{p}=.02$. Females were found to have a perspective that is more leaning toward the welfare of biodiversity than the males (Table 8).

Table 5. Chi-square test' $p$-values for respondents' profile and its relationship with knowledge and perspective

\begin{tabular}{ccc}
\hline \multirow{2}{*}{ Respondent's Profile } & \multicolumn{2}{c}{$p$-values } \\
\cline { 2 - 3 } & Knowledge & Perspective \\
\hline Age & .08 & .83 \\
Gender & .003 & .02 \\
Department & .003 & .41 \\
Environmental Education & .13 & .27 \\
\hline
\end{tabular}

Note: Confidence level $\alpha=0.05$

Table 6. Chi-square test's table of observed and expected values for gender and knowledge level

\begin{tabular}{cccc}
\hline & Observed Values & \\
\hline Knowledge Level & Female & Male & Grand Total \\
\hline Low & 4 & 17 & 21 \\
Moderate & 70 & 109 & 179 \\
High & 48 & 38 & 86 \\
Grand Total & 122 & 164 & 286 \\
\hline Knowledge Level & Female & Male & Grand Total \\
\hline Low & 8.96 & 12.04 & 21 \\
Moderate & 76.36 & 102.64 & 179 \\
High & 36.69 & 49.31 & 86 \\
\hline
\end{tabular}




\begin{tabular}{llll}
\hline Grand Total & 122 & 164 & 286 \\
\hline
\end{tabular}

Table 7. Chi-square test's table of observed and expected values for the academic department and knowledge level

\begin{tabular}{cccccc}
\hline \multicolumn{7}{c}{ Observed Values } \\
\hline Knowledge Level & DFES & D. Ind. Tech. & DIT & DE & Grand Total \\
\hline Low & 6 & 9 & 5 & 1 & 21 \\
Moderate & 44 & 79 & 56 & 0 & 179 \\
High & 25 & 19 & 41 & 1 & 86 \\
Grand Total & 75 & 107 & 102 & 2 & 286 \\
\hline \multicolumn{7}{c}{ Expected Values } \\
\hline Knowledge Level & DFES & D. Ind. Tech. & DIT & DE & Grand Total \\
\hline Low & 5.51 & 7.86 & 7.49 & 0.15 & 21 \\
Moderate & 46.94 & 66.97 & 63.84 & 1.25 & 179 \\
High & 22.55 & 32.17 & 30.67 & 0.60 & 86 \\
Grand Total & 75 & 107 & 102 & 2 & 286 \\
\hline
\end{tabular}

Table 8. Chi-square test's table of observed and expected values for gender and perspective

\begin{tabular}{cccc}
\hline \multicolumn{3}{c}{ Observed Values } \\
\hline Perspective & Female & Male & Grand Total \\
\hline Negative & 2 & 3 & 5 \\
Moderately positive & 81 & 82 & 163 \\
Positive & 39 & 79 & 118 \\
Grand Total & 122 & 164 & 286 \\
\hline \multicolumn{4}{c}{ Expected Values } \\
Perspective & Female & Male & Grand Total \\
\hline Negative & 2.13 & 2.87 & 5 \\
Moderately positive & 69.53 & 93.47 & 163 \\
Positive & 50.34 & 67.66 & 118 \\
Grand Total & 122 & 164 & 286 \\
\hline
\end{tabular}

The correlation between knowledge and perspective towards biodiversity was also tested. It was found that these two variables were weakly correlated with each other, $r(284)=0.39, p<.05$. The scatter plot showed a weak linear trend to describe the relationship between knowledge and perspective of students (Figure 1). 


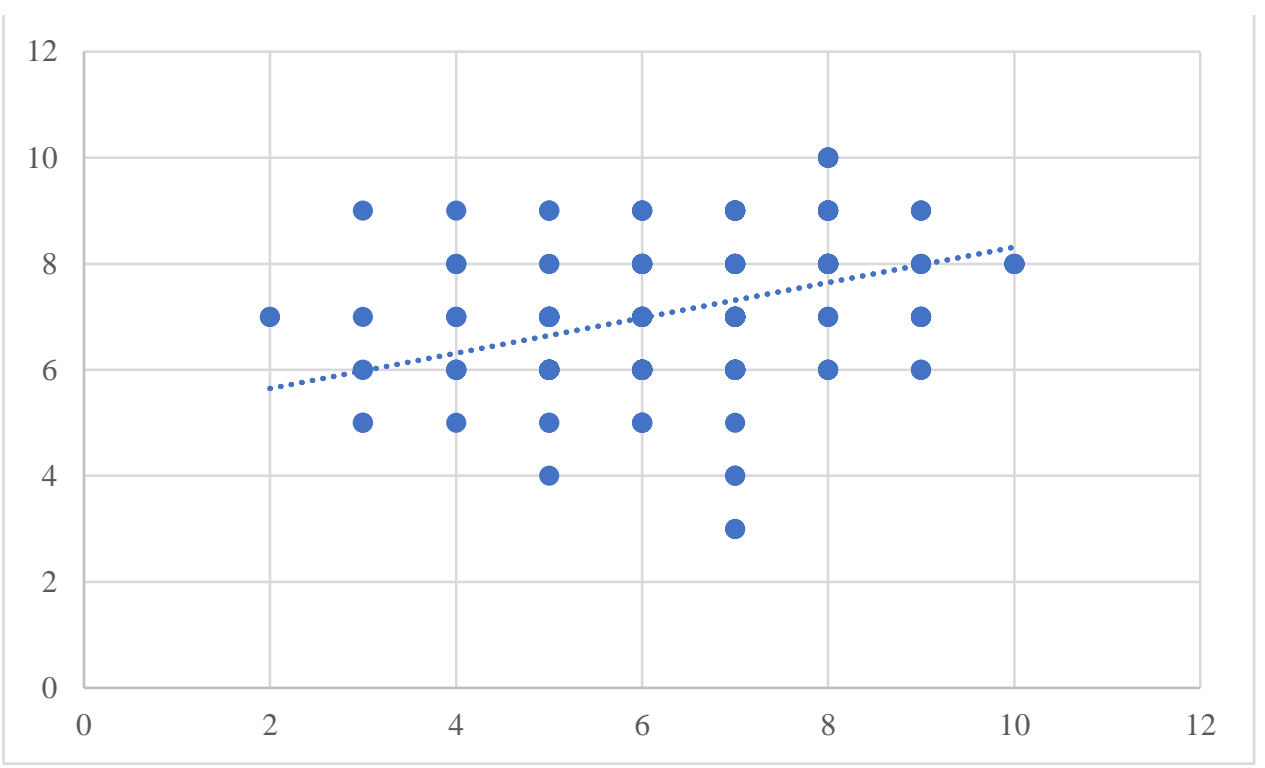

Figure 1. Scatter plot of the relationship between knowledge and perspective of students towards biodiversity

\subsection{Philippine Laws, Policies, and Projects on Biodiversity: Students' Knowledge and} Perspective

Among the 15 biodiversity-related laws included in the questionnaire, only 5 were known by more than 10 students (Figure 2). Executive Orders 26 and 193 or the "National Greening Program" was the most prominent which was known by $71(24.83 \%)$ students. This is alarming that the students are not familiar with the laws, policies, and programs of the Philippines towards the protection and improvement of the national biodiversity.

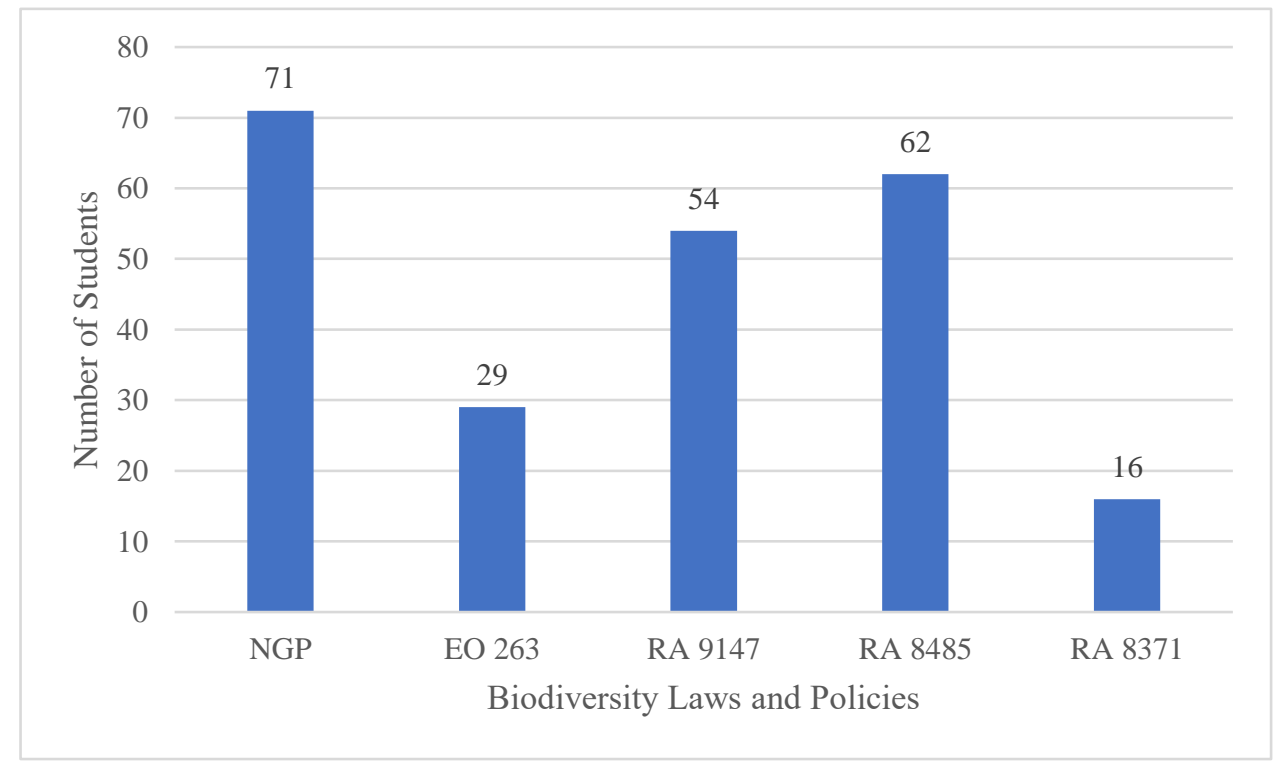

Figure 2. Top 5 Philippine biodiversity-related laws in terms of student knowledge and familiarity

However, it is reassuring to know that students are in favor of the government's effort to protect and improve the country's biodiversity. There were $284(99.3 \%)$ students 
who said that they are in support of the national agenda to protect and conserve biodiversity. Only 2 students were against the implementation of biodiversity laws and policies because they do not want the government to control people's lives. They are unaware that protecting biodiversity can provide other services to the present and future generation if it will be conserved. On the other hand, most of the students who were probiodiversity laws reasoned out that biodiversity shall be protected and sustainably utilized because of the ecosystem services it provides such as the provision of food and medicine, shelter, and even protection from disasters and calamities. Below are some of the notable statements from the students.

"I am pro because the said government activities will help sustain our biodiversity which will only lead to positive results."

"I am pro because it will save our mother nature as well as our biodiversity. Biodiversity can help us in many ways. It can protect us from natural phenomena, hunger, and it can provide our food and medicine. Government activities on biodiversity conversation and protection are a great help to us because these can preserve biodiversity for the future. Always remember that nature can live without people, but people can't live without nature."

"I support the government programs that aim to protect biodiversity because these have great contributions to our daily lives. It can provide us with so many services such as clean air, livelihood, and protection against natural calamities. So, it is important to preserve biodiversity."

"To avoid calamities like a flash flood or other manmade calamities and also through protecting biodiversity, we can avoid pollution and avoid polluting air and maintain our environment clean and fresh."

\section{Discussion and Conclusion}

This study revealed that the students were highly aware of the fact that biodiversity is everywhere. However, they also believed that biodiversity only covered the variability of life forms in terrestrial ecosystems. According to Colwell in 2009, covers the variability of life on Earth including those in aquatic and terrestrial ecosystems [30]. These results were somehow contradicting. Students believed that biodiversity is everywhere but has low knowledge about the more detailed and scientific definition of biodiversity specifically on terms such as terrestrial and aquatic ecosystems. This is highly anticipated as supported by the study of Jiwa and Esa in 2015 where $93.4 \%$ of the students can define biodiversity correctly, and $53.8 \%$ of them only defined students as "variability of life" lacking information on the ecosystems where it can be found [31]. Therefore, it can be said that students at ASCOT also had relatively high knowledge in terms of the basics about biodiversity, but not in its more detailed and technical aspects. Overall, with a mean score of 6.65 , students had a generally moderate knowledge on biodiversity.

With regards to their perspective on biodiversity, almost $100 \%$ of the students are willing to reuse, reduce, and recycle. This strategy is well known as the "3Rs Strategy" which was considered as a great impact on biodiversity protection particularly in preventing habitat loss and leaching due to overwhelming high amount of waste and improper waste disposal. Moreover, most of the students also believed that their individual actions can help save and protect biodiversity. It cohered with the study findings of a study which revealed that $90 \%$ of the students at Cyprus University of Technology were optimistic about the power of their contribution to protect biodiversity [32]. However, 90\% of students preferred to utilize invasive species. According to Gallardo et al. in 2019, invasive species are the main reason for species extinction and ecosystem degradation [33]. Nevertheless, based on the results of their knowledge test, they lack awareness on the technical aspect of biodiversity. Thus, it is assumed that, these responses were also brought about by this reason, lacking knowledge on the term 
"invasive species". Overall, students' perspectives were leaning towards the welfare and protection of biodiversity considering the overall mean score of 7.2.

The test on the relationship between students' profile and knowledge level revealed that gender and academic department had significant effect on the knowledge level of students. Females were found to have more knowledge and more positive perspective towards biodiversity. Women, in general, are always marginalized in terms of addressing biodiversity issues and challenges when they also have the knowledge and potential to contribute [32]. CBD believed that women have unique knowledge on biodiversity that they developed being marginalized. Two departments, DFES and DIT, had more knowledge on biodiversity compared to other departments. It is expected for DFES to be highly aware since it is where forestry students are enrolled. On the other hand, the test on the relationship between students' profile and perspective revealed that males had chosen positive actions and perspectives leaning to the welfare of biodiversity. CBD also highlighted that it could be because men are those who are mostly exposed in the field where actual protection and conservation measures are actually executed. For the relationship between knowledge and perspective, it was found to be weakly correlated. However, it is good to know that the correlation was positive even if it is weak. Educating students can provide a chance to improve the perspective and value allottment of students by improving their knowledge as a number of studies suggest $[22,35,36]$.

Lastly, the students had low knowledge and awareness on the numerous laws, projects and policies on biodiversity conservation and protection. This must be addressed properly as a citizen of the country who must do the duties and responsibilities as stated in these laws. Also, being knowledgeable about the environmental laws and principles of natural systems can help develop practical skills and improve students' ability to assess and prioritize the welfare and status of the environment [37]. Thus, students must be well aware of these environmental laws in the Philippines. However, it is a good sign that almost all students agreed to the intention of these laws in protecting biodiversity. They highly appreciate the fact that ecosystem services and protection has been and will continue to be rendered by biodiversity in the future if taken care of, properly.

Biodiversity is really important. As an implication of these results, the program curricula of all the degree courses shall be revisited. The administration must assure that students from each degree program are environmentally educated with emphasis on biodiversity. Therefore, each curriculum shall have at least one course (e.g., Environmental Science, Environmental Management, People and Ecosystems) to help them environmentally knowledgeable and ecologically conscious as aimed by RA 9512 in the Philippines. It is good that there is already a law that concerns the environmental education. However, it can be more comprehensive and useful if there will be a provision highlighting biodiversity education or the focus on biodiversity. It is highly needed since the rich biodiversity in the Philippines continues to decrease through years. The next generation shall be well-aware and concerned about these issues.

Funding: Please add: This research received no external funding.

Acknowledgments: The authors would like to thank the student participants of this study. Gratitude is also expressed to Dr. Eutiquio L. Rotaquio for the unending support to the faculty and staff of the college.

Conflicts of Interest: The authors declare no conflict of interest.

\section{References}

1. International Fund for Agricultural Development. Environment and natural resource management; IFAD: Italy, $2012 ; 47$ pp. 
2. FAO. Global Forest Resource Assessment 2010: Definition of Terms; FAO: Italy, 2010. 27 pp.

3. DeLong, D. Defining Biodiversity. Winter 1996, 24, 738-749.

4. Rawat, U.S; Agarwal, N. Biodiversity: Concept, Threats and Conservation. Env. Con. J. 2015, 16, 19-28.

5. van Weelie, D.; Boersma, K. Recontextualising biodiversity in school practice. J. Biol. Educ. 2018, 52, $262-270$.

6. Kumar, P.; Mina, U. Fundamentals of Ecology and Environment, $2^{\text {nd }}$ ed.; Kumar, P., Mina, U., Eds.; Pathfinder Publication: New Delhi, India, 2018; 240 pp.

7. Coracero, E.E.; Malabrigo, P.L. Carbon Storage Potential of the Tree Species along the Ultramafic Forest in Sitio Dicasalarin, Barangay Zabali, Baler, Aurora, Philippines. AIMS Environ. Sci. 2020, 7, 589-601.

8. Bogan, E.; Stan, D.; Vărvăruc, D. The impact of anthropogenic activities on components of the natural environment of the Titu Plain. Georeview 2015, 24, 54-64.

9. Raga, J. Role of Peoples and Nations in Protecting the Natural Environment. Acta 2013, 18, 142-176.

10. Basir, S.; Ming, K. Saving the Environment and the Dilemma of Finding the Right Solution. EpSBS 2019, $103-115$.

11. Kelkar, M. Local Knowledge and Natural Resource Management: A Gender Perspective. Indian J. Gend. Stud. 2007, 14, 295-306.

12. Boland, R.; Tenkasi, R. Perspective Making and Perspective Taking in Communities of Knowing. Organ. Sci. 1995, 6, 350-372.

13. Rwanamiza, E. Knowledge, Education, Learning and Teaching: Meanings and Relationships. J. Amer. Ass. Adv. Curr. Stud 2009, 5, 1-20.

14. Morar, F. \& Peterlicean, A. The role and importance of educating youth regarding biodiversity conservation in protected natural areas. Procedia Econ. 2012, 3, 1117 - 1121.

15. Howe, C. The Role of Education as a Tool for Environmental Conservation and Sustainable Development. Dissertation, Imperial College London, July 2009.

16. Kruglanski, A.; Baldner, C.; Chernikova, M.; Destro, C.; Pierro, A. A new perspective on the attitude behavior relation: The essential function of goals. Pol. Psycho.l Bull. 2018, 49, 31-39.

17. Šorytė, D. \& Pakalniškienė, V. Why it is important to protect the environment: reasons given by children. Int. Res. Geogr. Environ. 2019, 228-241.

18. Official Gazette. Available online: https://www.officialgazette.gov.ph/2008/12/12/republic-act-no-9512/ (accessed on 20 March 2021).

19. Ejem, L.; Bello, A. Environmental Awareness, Literacy, and Biodiversity Conservation Practices of Freshmen Students in Bukidnon State University, Philippines. JPAIR Institutional Research Journal 2013, 1, 68-84.

20. Navarro-Perez, M.; Tidball, K. Challenges of Biodiversity Education: A Review of Education Strategies for Biodiversity Education. Int. Electron. J. Environ. Educ. 2012, 2, 13-30.

21. Ramadoss, A.; Poyya Moli, G. Biodiversity Conservation through Environmental Education for Sustainable Development - A Case Study from Puducherry, India. Int. Electron. J. Environ. Educ.2011, 1, 97-111.

22. Lindemann-Matthies, P.; Constantinou, C.; Junge, X.; Köhler, K.; Mayer, J.; Nagel, U.; Raper, G.; Schüle, D.; Kadji-Beltran, C. The integration of biodiversity education in the initial education of primary school teachers: four comparative case studies from Europe. Environ. Educ. Res. 2009, 15, 17-37.

23. Hernandez, L.; Zamudio, K.; Drake, A.; Smith, M. Implementing team-based learning in the life sciences: A case study in an online introductory level evolution and biodiversity course. Ecol. Evol. 2020, 11, 3527-3536.

24. Nolan, K. Biodiversity Education and Sustainability Consciousness - A study on the effect of biodiversity education on the sustainability consciousness of Irish Primary School Students. Master's Thesis, Linköping University, 2020.

25. Almeida, A.; Gaerlan, A.; Manly, N. Research Fundamentals: From Concept to Output. Adriana Publishing Co., Inc.: Philippines, 2016.

26. Kahraman, S. Evaluating University Students' Understanding of Atmospheric Environmental Issues Using a Three-Tier Diagnostic Test. Int. Electron. J. Environ. Educ. 2019, 9, 1-17.

27. Kershaw, J.; Ducey, M.; Beers, T.; Husch, B. (2017). Forest Mensuration, $5^{\text {th }}$ ed.; John Wiley \& Sons, Ltd., UK; Hoboken, NJ, USA, 2016; ISBN 978-1-118-90203-5.

28. Ugoni, A.; Walker, B. The Chi square test: an introduction. Comsig Review 1995, 4, 61-64.

29. Schober, P.; Boer, C.; Schwarte, L.A. Correlation Coefficients: Appropriate Use and Interpretation. Anesth. Analg. 2018, 126, 17631768.

30. Colwell R.K. Biodiversity: Concepts, Patterns and Measurement. In The Princeton Guide to Ecology; Levin, S., Eds.; Princeton University Press: Princeton, New Jersey; pp. 257-263.

31. Jiwa, R.; Esa, N. Student Teachers' Knowledge of Biodiversity. Int. J. Sci. Res. Pub. 2015, 5, 1-4.

32. Nisiforou, O.; Charalambides, A. Assessing Undergraduate University Students' Level of Knowledge, Attitudes and Behaviour Towards Biodiversity: A case study in Cyprus. Int. J. Sci. Educ. 2012, 34, 1027-1051.

33. Gallardo, B.; Bacher, S.; Bradley, B.; Comín, F.; Gallien, L.; Jeschke, J.; Sorte, C.; Vilà, M. InvasiBES: Understanding and managing the impacts of Invasive alien species on Biodiversity and Ecosystem Services. NeoBiota 2019, 50, 109-122.

34. Convention on Biological Diversity. Available online: https://www.cbd.int/gender/doc/cbd-towards2020-gender integrationen.pdf (accessed 10 March 2021).

35. Venuste, N.; Olivier, H.; Valens, N. Knowledge, attitudes and awareness of pre-service teachers on biodiversity conservation in Rwanda. Int. J. Env. Sci. Educ. 2017, 12, 643-652.

36. Nyberg, E.; Castéra, J.; Mc Ewen, B.; Gericke, N.; Clément, P. Teachers' and Student Teachers' Attitudes Towards Nature and the Environment-A Comparative Study Between Sweden and France. Scand. J. Educ. Res. 2020, 64, 1090-1104. 
37. Erhabor, N.; Don, J. Impact of Environmental Education On the Knowledge and Attitude of Students Towards the Environment. Int. J. Env. Sci. Educ. 2016, 11, 5367-5375. 